\title{
BUSINESS STUDENTS' UNDERSTANDING OF LINGUISTIC AND CULTURAL ISSUES RELEVANT TO THE GLOBAL WORKPLACE
}

\author{
Carmela Briguglio \\ Curtin Business School \\ Curtin University, GPO Box U 1987 \\ Perth, Western Australia 6845 \\ Tel: +61892663079 \\ Email: c.briguglio@ curtin.edu.au
}

\begin{abstract}
This study sought to explore business students' understanding of linguistic and cultural issues relevant to the global workplace and whether students feel their courses equip them with the skills needed to interact effectively in multinational teams. The article reports the findings of a case study that was implemented at Curtin University of Technology in Western Australia with a class of undergraduate business students undertaking a third year unit in 'International Management'. The data were collected through a questionnaire designed for this purpose. The findings suggest that while students are quite knowledgeable about linguistic and cultural issues relevant to the global workplace, they are also aware that they may not have the intercultural communication skills needed to operate confidently and successfully in multinational teams and global workplaces.
\end{abstract}

Keywords: Intercultural Communication; Multinational Teams

Business Communication.

\section{Introduction}

The phenomenal spread of English as a global language, particularly in a business context (Crystal 1997; Brutt-Griffler 1998; Graddol 2000 \& 2006) makes it imperative for people to become more proficient in intercultural communication. For while some may think that the spread of English around the world will make communication easier and that if one is a speaker of English, a 
little knowledge of the 'other' culture will suffice to ensure effective intercultural communication, nothing could be further from the truth. The global spread of English, in fact, makes the situation more complex (Kachru 1992; Scollon \& Scollon 1995; Crystal 1997; Graddol \& Meinhof 1999, Zachary 2003; Liddicoat, Eisenchelas \& Trevaskes 2003). Indeed as Garcia and Otheguy (1989, p.2) state, "a serious consequence of the spread of English has been that it has created a false sense of mutual intelligibility". This being the case, it becomes imperative for business students to develop intercultural communication skills, since multinational/multicultural teams are likely to become an increasing feature of the future business landscape (Smith \& Berg 1997; Distefano \& Maznevski 2000). One of the ways to develop intercultural communication skills in university settings is by having students work in multinational/multicultural teams (Crosling \& Ward 2001; Crosling \& Martin 2005; Briguglio 2005). However, previous research undertaken in Australia (Hawthorne 1997; Nesdale \& Todd 1997; Volet \& Ang; 1998 Briguglio 2000) indicates that if students are left to their own devices, they will often team up with others from similar nationalities/cultural backgrounds.

For this case study, implemented at Curtin University of Technology in Western Australia with a class of undergraduate business students undertaking a third year unit, teams were deliberately structured to be multinational. This was a two-stage case study. The first stage aimed to ascertain what business students already know about cultural and linguistic issues relevant to the global workplace and to what extent they perceive that language and intercultural communication skills are being developed in their course. The second stage involved implementing a structured intervention with the aim of developing intercultural communication skills and establishing whether the intervention was successful. This paper describes the characteristics of the class that was selected and the findings of the first stage of the case study.

\section{Student multinational/multi-ethnic teams}

In regard to group or team work in tertiary settings, a project on 'Managing Student Teams' undertaken at The University of Western Australia (Caspersz, Skene \& Wu 2002, 2004 \& 2005; Caspersz, Wu \& Skene 2002) was of particular interest. This project, which is still ongoing, has examined such issues as student willingness to participate in team projects and issues of intra-group trust, as well as gender and country-of-origin effects on team performance. Project findings indicate that individual team member performance can be affected by gender and country-of-origin factors. Studies in the UK by De Vita (2002a \& 2002b) show that students had similar concerns to those found by Caspersz et al (2002a): for example a belief that multicultural teams might negatively impact on assessment results. 
Volet and Ang (1998) examined similar issues in an Australian setting with particular emphasis on culturally mixed groups. They were keen to probe the reasons why there is a lack of mixing between Australian and international students in Australian universities (see also Hawthorne 1997; Nesdale and Todd 1997; Briguglio 2000) and to explore the experiences of students in culturally mixed groups for the completion of assignments. Volet and Ang found a variety of reasons why students initially preferred to work in culturally/nationally homogenous groups, not least the sense of belonging, bonding and familiarity provided by a peer group comprising the same or a similar culture. Importantly, they found that where students had been forced by circumstances to form culturally diverse groups, both Australian and international students had found the experience to be reasonably positive. Unfortunately, such an experience was not enough to encourage students to seek further involvement in culturally diverse teams, leading the authors to conclude that "unless cultural contact is engineered as part of formal study, social cohesion will not happen and all students will miss out on critical learning opportunities" (Volet \& Ang 1998, p.9).

In the US, Schullery and Gibson (2001) found a reluctance on the part of students towards working in assignment groups. Various studies have therefore concluded that student group work, particularly in multicultural/multinational teams, needs to be well-structured (Smart, Volet \& Ang 1998; Cheney 2001) and well-managed (Schullery \& Gibson 2001; Casperz et al. 2004 \& 2005) and that students need to be taught the necessary skills (Crosling and Martin 2005) in order to achieve sound learning outcomes.

The multinational teams case study

An undergraduate class undertaking a third year level unit in International Management was considered appropriate for this case study. The researcher approached a colleague teaching the unit, who was keen for his class to take part in the case study. The researcher was not involved in teaching this class and students were made aware that their responses would therefore have no impact on their mark in this unit. Assessment for the unit included a group assignment, a common assessment task in business education courses in Western Australia. A group project or assignment involves students working in teams (both in and out of class time) and often has an oral and/or a written component for assessment. The aim was to have students in an educational context using 'English as a global language' for intercultural communication in multicultural/multinational teams. Students were informed by their lecturer that assignment teams would be deliberately structured to be multinational. The set task required teams to research a topic relevant to international management and present their findings orally in a 20 minute presentation (worth $10 \%$ of total mark) and in writing in a 3,000 word formal research paper (worth $20 \%$ of total mark). 
This part of the Multinational Teams Case Study aimed to:

1. explore the knowledge and attitudes of a group of undergraduate business students about linguistic and cultural issues in international business contexts; and

2. identify the attitudes of such students towards working in multinational student groups/teams.

A questionnaire was developed to gather data on the above. The questionnaire was divided into five sections, as described below, with room for written comments at the end of each section:

- Part A, student information: this included gender, whether local/Australian or international student, nationality/cultural background, and information on languages known.

Parts $B, C, D$ and $E$ each consisted of a 5 point Likert scale with 1, 'strongly disagree', 2, 'disagree', 3 'unsure', 4 'agree' and 5, 'strongly agree', which aimed to ascertain students' attitudes in each of the following areas:

- $\quad$ Part B, English language and other languages and cultures in Australia

- $\quad$ Part $C$, English as a global language in busines.

- $\quad$ Part D, Previous experience with group work

- $\quad$ Part E, Forthcoming group task for this unit.

Twenty-eight (28) questionnaires were completed by students in the selected class during class time in the first week of semester. A statistical analysis of the questionnaire results was undertaken using SPSS and generating mean responses. The comments section was analysed by sorting and sifting qualitative data to elucidate major themes.

\section{Findings and discussion}

\section{Characteristics of the cohort}

The cohort consisted of 28 students, of whom 15 were male and 13 female. Thirteen students described themselves as 'local/Australian' and 13 as 'international students' (two missing responses). There were 12 different nationalities/cultural backgrounds represented in the sample group, almost one third of whom were Australians, while others came from China, Croatia, Germany, Indonesia, Kenya, Malaysia, Norway, Taiwan, Thailand, Turkey and USA. Students were almost equally divided between those in the 17-21 year old age bracket and those in the 22-33 year old age bracket. 


\section{Perceptions regarding English language and other languages/cultures in Australia}

This section of the questionnaire sought to determine students' attitudes and beliefs about: the use of English and other languages in Australia; their own fluency in English macro-skills, particularly in regard to their studies; and how much they felt their studies were developing their oral and written skills in English. The results indicate that students consider English is very important in Australia and for their studies. There was a high level of agreement with the statement "I need to use English every day", although responses to other questions indicate that among these students there is also a fairly high use of other languages and some code switching. This would be expected, since, as was indicated above, there were 12 nationalities represented in the cohort and a large proportion of the students were bilingual.

Questions relating to perceptions about students' ability with written and spoken English showed students felt that their linguistic and intercultural communication skills were being developed through their tertiary studies. However, responses also indicated that a number of students have some difficulty in understanding people with accents, and a few expressed difficulty with understanding international students in class.

The following comment indicates students' understanding of the importance of English as a global language and for their studies:

English is very important because it's a global language and without knowing English [I will] hardly achieve success in my future career (Indonesian student).

Another comment illustrates that students are aware of Australia's multicultural society, but do not feel that this is without its problems:

I think that we have an extremely multicultural society but with all the different languages, it's sometimes hard to communicate with others or understand them when they're not fluent in English (Australian student).

Concerns are also expressed about understanding different accents in English but not only by first language (L1) speakers;

It is difficult sometimes to understand people with an accent (Indonesian student).

Other comments reflect both positive and problematic aspects of linguistic and cultural issues at tertiary level: 
The various cultural backgrounds at Curtin are great; when you look at the percentage of international students to local students, however, it's very hard to understand and to learn to the best of your ability when you have a non-first language English speaking lecturer or tutor (Australian student).

One comment illustrates very well the fact that students do not necessarily learn from each other simply because they are "thrown together" in multinational groups:

When working in multicultural groups students aren't getting to know each other in a personal way; we get together to do group work etc but we are not really learning about their culture, beliefs, values much at all. We learn a little, but not much (Australian student).

And finally one comment reflected a very sophisticated understanding of language and culture issues related to tertiary curriculum:

I think that even though there are attempts to include cultural diversity as an issue into unit curriculums, it is still included rather ethnocentrically, ie always presenting Australia/America as the 'norm' and other countries/cultures only with reference to how they relate to Australia and the US (Australian student, self-declared "Dutch and Italian parents").

On the whole, student responses to questions in Part B of the questionnaire seem to indicate that students feel their university course is preparing them reasonably well for the global world of business, with relevant questions drawing moderately high levels of agreement. This includes developing both their English language skills as well as their knowledge of other cultures and intercultural communication. For example:

- $\quad 75 \%$ agreed that through their studies they 'learn a lot about intercultural communication';

- $75 \%$ agreed that they learn a lot about other cultures from their study materials;

- $\quad 82.2 \%$ agreed that their studies have developed their interpersonal skills; and

- $\quad 82.1 \%$ agree that they have learned a lot about other cultures through mixing with a multinational student population. 


\title{
Perceptions regarding English as a global language and intercultural communication issues in business
}

Part $\mathrm{C}$ of the questionnaire sought to probe students' understanding of issues surrounding intercultural communication, particularly in a business context. Responses to questions which asked students whether they felt their studies at Curtin were preparing them for intercultural/ international business contexts show a reasonably high level of agreement, indicating that students feel they are being well prepared for the world of business through their tertiary studies.

Student responses to Part $\mathrm{C}$ reflect a quite sophisticated understanding of linguistic and cultural matters. Students indicated that they are aware of the importance of English as a global language for business, but not unaware of the importance of other languages and bilingualism.

\begin{abstract}
Although English is becoming a global language, as an international businessperson, you still need to have an understanding of different cultures and customs to help trade (Australian student).
\end{abstract}

I think people in other countries speak English for business purposes, but I don't think that English is the only language that should be used in business (Croatian student).

Students were able to give other reasons why other languages are also important in business:

English is not spoken globally and it depends on where you want to do business whether English is relevant or not (Norwegian student).

I guess learning another language besides English would be useful. Your business partner will give you more respect if you can speak their language (Indonesian student).

The rates of agreement for the first two statements in Part C are not very high. Only $50 \%$ of students agreed or strongly agreed with the statement that 'speakers of English as a first language will be those with the greatest advantage in international business' and $61.4 \%$ that 'in order to communicate in international business contexts you have to speak English'. Rates of agreement were similar for the statement, 'I think business people in most countries speak English nowadays' (60.7\%). And students' response to the statement 'because English is becoming a global language, in the future that's all people in business will need to speak' (35.7\% agree or strongly agree, $42.8 \%$ disagree or strongly disagree) shows they are not too naïve. Nor are they naïve about the fact that intercultural communication is more than 'being nice to people from other countries' (only $28.5 \%$ agreement). A high level of disagreement $(82.2 \%$ ) with the 
statement 'English is the only business language in Asia' shows students understand that other languages are used in the region besides English; and only 17.9\% agreed with the statement 'most people in Asian countries speak English'.

Student responses to other questions in Part C indicated that they value and are aware of the importance of other languages and cultures. Statements which drew the highest rate of agreement in this section included the following: 'bilingual speakers will be those who are most advantaged in international business contexts' (with $92.8 \%$ agreement); 'it is important to know something about other languages and cultures in order to be a good communicator in international business' (with 100\% agreement); and 'it is important to know something about intercultural communication in order to be a good international manager'(with 100\% agreement).

There is some awareness that English is not the same all over the world, and some students indicated they are aware of varieties of English:

I have found that English language changes across different countries, eg Australia versus America (Australian student).

Similarly, there was a fairly high level of disagreement expressed with the statement 'Asian students speak English just like Australians' (75\% disagreement) and the statement 'the only difference between Australian English and English spoken in Asia is the accent' (64.2\% disagree and $25 \%$ are unsure). Students also showed they understand that intercultural communication is not straightforward. The statement 'there can be misunderstandings when people from different cultural backgrounds speak English' drew an $82.2 \%$ rate of agreement, while only $57.2 \%$ agreed with the statement 'it's up to people who are not native speakers of English to make the effort to communicate effectively', showing some understanding that responsibility for intercultural communication is two-way, that is for interpretability as well as intelligibility (Candlin 1982; Garcia \& Otheguy 1989; Kim 1991 \& 2001; Smith 1992; Jenkins 2000). Future successful intercultural communication will be the responsibility of both parties engaged in interaction, be they first or second language speakers of English. To be a good communicator in English in future is likely to require one to have, as well as a mastery of English, the ability to understand at least some varieties of world English and English accents, as well as intercultural knowledge.

\section{Previous experience with group work and perceptions about forthcoming group task}

Part $D$ of the questionnaire aimed to gauge students' feelings about previous experiences and gender, cultural and linguistic issues in multinational student 
teams. Part E, the last section of the questionnaire, aimed to isolate students' feelings about the forthcoming group task (ie working in multinational student teams) for this unit of study. Parts $D$ and $E$ of the questionnaire draw on the research about multinational student teams undertaken by Volet and Ang (1998) and Caspersz, Wu \& Skene (2002b).

Analysis of this part of the questionnaire shows that students are reasonably confident that the forthcoming experience of working in multinational teams will be positive. However, there is some concern about the time the assignment will take and the possible negative effect on the overall group mark. For example, it seems some students worry about having to do more work than other group members and that group work takes too much time. Student responses indicate that students have experienced some problems with working in teams before, but that, nevertheless, they consider there is a lot to be learned from group processes and they do not necessarily prefer working alone.

Students acknowledged the benefits of working in 'mixed nationality' teams, but also expressed some caution about possible problems. They thought they would learn a lot about culture through working in multinational teams but there was also moderate agreement with the idea that relationships in mixed nationality teams could be difficult. In regard to gender issues, both female and male students seem to prefer working with females slightly more than with males, but prefer mixed gender groups overall.

Responses to questions which address personal and self-efficacy issues, seem to reflect the findings of Caspersz, Wu \& Skene (2002). There was a reasonably high level of agreement with statements about wanting control over quality of the assignment, wanting to be liked by group members and confidence in being able to work effectively in a multinational team. Student responses indicated that students are aware they may still have a lot to learn, but they are confident they will learn from the forthcoming group task. Finally students did not have biases about either international or 'Australian' students being more hardworking.

Written comments in sections $D$ and $E$ reflect earlier good and bad experiences students have had with group assignments as well as some concerns about the forthcoming group task. The following comment reflects the haphazard nature of experiences in students groups: 
Some groups work well, some are really dysfunctional. Luck of the draw, really (Australian student).

Other comments reflect some concerns about the forthcoming group task:

In the past, group work has been a great experience for me, I tend to have group members who are from Australia or who speak English as a first language. [With the forthcoming group assignment] I'm a little unsure about how well we will function and how well the group will complete the assignment. I'm also worried about the workload that I'm going to have as the only Australian (Australian student).

Some students were very specific about their concerns:

"Social loafing" is the worst thing in a group - people who slack off and put in less effort. The best group depends on the people - if all are high achievers, ambitious [then] the project will be right on track (Chinese student).

Finally, two comments reflect the complex group dynamics of multinational teams and the misunderstandings that can arise, with Australian students thinking that international students are "under-performing", while international students feel that they are not listened to:

I find it difficult to communicate with and understand people from different cultures and have felt that I carried more of the workload and did not complete the assignment as well as I could have if I was working on my own (Australian student).

I find on many occasions while working on assignments or presentations, that Australians tend to be more dominant in discussion and therefore international students do not participate and tend to allow others to talk (Malaysian student).

Thus responses to part $\mathrm{D}$ of the questionnaire reflected the sorts of concerns that have previously been raised about undergraduate team assessment projects in Australian contexts (Volet and Ang 1998; Briguglio 2000; Caspersz, Skene and Wu 2002a \& 2002b) as well as in the UK (De Vita 2002) and US (Schullery \& 
Gibson 2001). They tended to indicate that, based on previous experience, students had some reservations about group work in multinational student teams. For example, only $60.7 \%$ had found previous group experiences to be positive while $70.3 \%$ indicated that they had experienced problems with previous group work. In fact, responses in this section reflect students' concerns that: they may have to 'carry' others; group work will take too much time; relationships with other students are more difficult in multinational teams; and multinational teams do not necessarily produce better assignments. De Vita (2002) found similar concerns among UK students, as did Caspersz et al. (2002a) among Western Australian students.

Nevertheless, students are still convinced that they can learn from multinational groups, with $60.7 \%$ indicating that they learned a lot about other cultures through group work ( $21.4 \%$ unsure) and $53.6 \%$ believing people from other nationalities work just as hard as they do ( $28.6 \%$ unsure). And only $32.1 \%$ agreed that they would prefer to work alone rather than in a group $(46.4 \%$ disagree).

Similarly, in part $\mathrm{E}$ of the questionnaire students indicated that although they have some concerns about the forthcoming group task, they feel they can learn from it and they are confident they can work effectively with people from different cultural backgrounds and reflect high levels of self-efficacy. The much lower agreement on questions relating to assignment results indicates students' insecurity about the forthcoming task and reflects De Vita's (2002a \& 2002b) findings with UK students. Students are quite clear that they still have a lot to learn about working in multinational teams ( $92.8 \%$ agree), but they still feel fairly confident that they will learn a lot ( $82.1 \%$ agree) and more than half $(64.3 \%)$ believe that multinational teams could be more creative. Although $44.4 \%$ indicated they expected some difficulties because of the multicultural group, there did not seem to be a bias either way towards international or domestic students not working hard.

\section{Conclusion}

The questionnaire for this case study was designed particularly to ascertain business students' knowledge and understanding of international business and of working in multinational student teams, with the emphasis on intercultural communication. The results of the questionnaire indicate that students are, on the whole, reasonably knowledgeable of and well disposed to other languages and cultures, and that they are also aware that intercultural communication and working with people from different cultural backgrounds is not always easy. 
The results of this questionnaire provide a picture of the understanding and attitudes of a fairly 'typical' group of business students in an Australian tertiary institution towards linguistic and cultural issues in business. We have seen that students are equipped with some knowledge about cultural and linguistic matters and that while they are well disposed towards other cultures they understand that they still have a lot to learn. There was agreement by all students that they will require linguistic and cultural knowledge in order to be good communicators in international business. At the same time, in a 'multinational' situation closer to home, that is, multinational student teams, we have seen that students have concerns about how effective the intercultural experience will be, whether there might be conflict and misunderstandings in the group, and whether the result of the group task will come up to their expectations. Some of the literature reviewed, particularly that which refers to university contexts (Hawthorne 1997; Nesdale \& Todd 1997; Volet \& Ang 1998; Smart Volet \& Ang 2000; Briguglio 2000; Liddicoat, Eisenchelas \& Trevaskes 2003) would seem to indicate that not enough is being done to develop students' intercultural communication skills and to prepare students for communication in the global workplace.

\section{References}

Briguglio, C. (2000). Language and cultural issues for English-as-a-second/foreign language students in transnational education settings. Higher Education in Europe, 25 (3). 425-434.

Briguglio, C. (2005). The use of English as a global language in multinational settings and the implications for business education, PhD thesis. Perth, Western Australia: The University of Western Australia.

Brutt-Griffler, J. (1998). 'Conceptual questions in English as a world language: Taking up an issue', World Englishes. 17 (3) 381-392.

Candlin, C. (1982). English as an international language: Intelligibility vs. interpretability: Notes on a theme. In C. Brumfit (Ed.). English for international communication. New York: Pergamon.

Caspersz, D., Skene, J. \& Wu, M. (2002). Team members that bring you down dead: The antecedents of student willingness to participate in team projects. Paper presented at the Teaching and Learning Forum 2002. Perth: Edith Cowan University.

Caspersz, D., Wu, M. \& Skene, J. (2002). The influence of gender and country-oforigin effects on student processes in teams. HERDSA conference, Vol. 22.

Caspersz, D., Skene, J. \& Wu, M. (2004). An approach to managing diversity in student team projects. Teaching and Learning Forum, 2004. Perth: Murdoch University. 
Caspersz, D., Skene, J. \& Wu, M. (2005). Principles and guidelines in managing student teams. Teaching and Learning Forum 2005. Perth: Edith Cowan University.

Cheney, R. (2001). Intercultural business communication, international students and experiential learning. Business Communication Quarterly, 64 (4), 90105.

Crosling, B. \& Ward, I. (2001) Oral Communication: the workplace needs and uses of business graduate employees. English for Specific Purposes, 21, 4157.

Crosling, B. \& Martin, K. (2005). Student diversity and collaborative learning: A positive combination for curriculum internationalisation. In E. Manalo and G. Wong-Toi, Communication Skills in University Education: The international dimensions. Auckland: Pearson Educational.

Crystal, D. 1997. English as a global language. Cambridge: Cambridge University Press.

De Vita, G. (2002a). Cultural equivalence in the assessment of home and international business management students: a UK exploratory study. Studies in Higher Education, 27 (2), 221-231.

De Vita, G. (2002b). Does assessed multicultural group work really pull UK students' average down? Assessment and Evaluation in Higher Education, 27 (2), 153-161.

Distefano, J. \& Maznevski, M. L. (2000). Creating value with diverse teams in global management. Organizational Dynamics, 29 (1), 45-63.

Garcia, O. \& Otheguy, R. (eds.) (1989). English across cultures, cultures across English. New York: Mouton de Gruyter.

Graddol, D. \& Meinhof, U.H. (eds.) (1999). English in a changing world. AILA Review 13.

Graddol, D. (2000). The future of English. London: The British Council.

Graddol, D. (2006) English next. London: The British Council.

Hawthorne, L. (1997). The issue of racial cleavage on campus. Paper presented \& published in the proceedings of the $8^{\text {th }}$ national ISANA Conference, Melbourne, December 1997.

Jenkins, J. (2000). The Phonology of English as an international language. Oxford: Oxford University Press.

Kachru, B. (1992). 'World Englishes: approaches, issues and resources'. Language Teaching, 25 (1) 1-14. 
Kim, Y. Y. (1991). 'Cross-cultural interpersonal communication', in S. TingTwomey \& F. Korzenny (eds.), International and Intercultural Communication Annual, 15. Newbury Park: Sage Publications.

Kim, Y. Y. (2001). Becoming intercultural. Thousand Oaks, California: Sage Publications.

Liddicoat, A., Eisenchelas, S. \& Trevaskes, S. (eds.) (2003). Australian perspectives on internationalising education. Melbourne: Language Australia Ltd.

Nesdale, D \& Todd, P. (1997) Promoting international contact between

Australian and international university students. Journal of Higher

Education Policy and Management, 19 (1), 61-76.

Schullery, N. and Gibson, M. K. (2001). Working in groups: Identification and treatment of students' perceived weakness. Business Communication Quarterly, 64 (2) 9-30.

Scollon, R. \& Scollon W.S. (1995). Intercultural communication: A discourse approach. Massachusetts: Blackwell.

Smart, D. Volet, S. \& Ang, G. (2000). Fostering social cohesion in universities: Bridging the cultural divide. Canberra: AEI and DETYA.

Smith, L. E. (1992). Spread of English and issues of intelligibility, in B. Kachru (ed.), The other tongue: English across cultures. Chicago: University of Illinois Press, pp.75-90.

Smith, K. \& Berg, D. (1997). Cross-cultural groups at work. European Management Journal, 15 (1) 8-15.

Zachary, M. (Ed.) (2003). 'Five perspectives in intercultural business education'. Business Communication Quarterly, 66 (3), 73-96.

Volet, S. \& Ang, G. (1998). Culturally mixed groups on international campuses: an opportunity for intercultural learning. Higher Education Research and Development, 17 (1), 5- 23. 